\title{
The Decomposition of Shared Environmental Influences on Externalizing Syndromes in the Swedish Population: A Multivariate Study
}

\author{
Henrik Ohlsson, ${ }^{1, *}$ Kenneth S. Kendler, ${ }^{2,3,4, *}$ Paul Lichtenstein, ${ }^{5}$ Jan Sundquist, ${ }^{1,6}$ \\ and Kristina Sundquist ${ }^{1,6}$ \\ ${ }^{1}$ Center for Primary Health Care Research, Lund University, Malmö, Sweden \\ ${ }^{2}$ Virginia Institute for Psychiatric and Behavioral Genetics, Virginia Commonwealth University, Richmond, VA, USA \\ ${ }^{3}$ Department of Psychiatry, Virginia Commonwealth University, Richmond, VA, USA \\ ${ }^{4}$ Department of Human and Molecular Genetics, Virginia Commonwealth University, Richmond, VA, USA \\ ${ }^{5}$ Department of Medical Epidemiology and Biostatistics, Karolinska Institute, STH, Sweden \\ ${ }^{6}$ Stanford Prevention Research Center, Stanford University School of Medicine, Stanford, CA, USA
}

\begin{abstract}
Using information from Swedish population registries, we attempt to decompose the shared environment (C) into four subcomponents: close family, family, household, and community. Among pairs differing in their genetic and geographical/household relationships, we examine three externalizing syndromes: drug abuse (DA), criminal behavior (CB), and alcohol use disorders (AUD). The best-fitting common pathway model suggested that total estimates for $C$ were higher for DA ( $21 \%$ for males and $18 \%$ for females) than for AUD (16\% and 14\%) and CB (17\% and 10\%). Concerning syndrome-specific influences in males, close family effects were stronger for $C B$ and $A U D$, while community effects were stronger for DA. The two $C$ components in between community experiences and close family experiences (family and household) were estimated to almost entirely derive from the common latent factor. In females, among the four components of $C$, the community experiences were just slightly above zero, while the $C$ components referred to as the household effect were almost zero. The total close family experiences were similar and most important across syndromes were also divided into common and specific components. For all syndromes, for both males and females, the effects of additive genetic factors were 2-4 times the size of the total effect of the shared environment. Applying standard methods to novel relationships, we expand our understanding of how the shared environment contributes to individual differences in three externalizing syndromes.
\end{abstract}

Keywords: shared environment, close family, family, household, community, externalizing syndromes

Shared or common environment (C), along with genetic effects and individual-specific environment, has long been a key parameter in the quantitative genetic studies of individual differences in both model organisms and humans (Falconer, 1989; Lynch \& Walsh, 1998; Mather \& Jinks, 1982). Years ago, traditional quantitative methods proposed a decomposition of genetic effects into additive, dominance, and epistatic components (Falconer, 1989; Mather \& Jinks, 1982). With modern molecular methods, it is now possible to further sub-divide these genetic effects into the proportion that reflects common single-nucleotide variants, rare variants, and various genomic abnormalities (Lee et al., 2012; Purcell et al., 2009, 2014). By contrast, potential subcomponents of the shared environment have received less attention. The only subcomponents that are occasionally used in modeling are the special twin environment $(\mathrm{T})$ and the proportion of variance in shared environment resulting from parental behaviors (W; Truett et al., 1994).

There is an obvious reason for these developments. Examining only reared together twin pairs - by far the most popular design in human behavior genetics - permits only the estimation of a single parameter for the shared

ReCeived 13 April 2017; ACCePted 20 April 2017. First published online 5 June 2017.

ADDRESS For CORRESPONDENCE: Henrik Ohlsson, PhD, Center for Primary Health Care Research, Department of Clinical Sciences, Malmö (IKVM), Lund University, Jan Waldenströms gata 35, SE-20502 Malmö, Sweden. E-mail: henrik.ohlsson@med. lu.se

* These authors contributed equally to this work. 
environment. Including full siblings permits the addition of the special twin environment. Studying parents in twinfamily designs can allow the estimation of a shared environment resulting from parental behaviors. So, estimation of sub-components of the shared environment depends critically on the availability of informative samples.

In a thoughtful review paper, Burt effectively countered the claims of the influential article by Plomin and Daniels (1987) that shared environmental effects are of limited import for psychological, psychiatric, and behavioral traits. She conducted a meta-analysis of twin and adoption studies of internalizing and externalizing psychopathology through adolescence, concluding that $\mathrm{c}^{2}$ estimates for most traits were in the range of $10-20 \%$. She also noted that shared environmental influences are typically stable, unlikely to be artefactual, and may be particularly important in high-risk environments. In a subsequent review, Burt (2014) noted the limitations of the traditional twin design for the study of the shared environment and makes the important point that 'shared environmental influences are not restricted to familial influences' (p. 307). Community and school effects, she observed, both directly and as proxies for other influences like peer deviance, likely contribute to $\mathrm{c}^{2}$ estimates. Finally, in a recent empirical study, Burt et al. (2015) showed, using community samples, a substantial impact of neighborhoods on the key externalizing dimension of rule breaking.

In this report, congruent with the research perspective articulated by Burt, we attempt to sub-divide the shared environment into four subcomponents termed (1) close family, (2) family, (3) household, and (4) community. This has been made possible by using Swedish population registries that contain the informative relationships necessary to estimate these parameters.

We examine three externalizing syndromes that we have previously examined in Sweden using both adoption and traditional twin or twin-sibling designs: drug abuse (DA; Kendler, Maes et al., 2013; Kendler et al., 2012), alcohol use disorder (AUD; Kendler, Ji et al., 2015; Kendler, Lonn et al., 2016) and criminal behavior (CB; Kendler, Larsson Lönn et al., 2014; Kendler, Maes et al., 2015). We study these disorders because, unlike more traditional psychiatric disorders where shared environmental effects are difficult to detect, we have, for all of them, found both evidence for substantial shared environmental effects in standard twin or twin-siblings studies (Kendler, Lonn et al., 2016; Kendler, Maes et al., 2015; Kendler, Maes et al., 2013) and for an impact on risk in adoptees of adoptive family characteristics (Kendler, Ji et al., 2015; Kendler, Larsson Lönn et al., 2014; Kendler et al., 2012). Evidence for shared environmental effects for these syndromes has also emerged from other twin samples for DA (Kendler et al., 2003) and AUD (Kendler et al., 1997; McGue et al., 1992), and from meta-analyses of twin and adoption samples for externalizing/antisocial behavior (Rhee \& Waldman, 2002) and AUD (Verhulst et al.,
2015). Furthermore, with a common pathway model fitted to monozygotic (MZ) and dizygotic (DZ) twin pairs, we have found evidence of both shared and unique genetic and common environmental effects (Kendler, Lonn et al., 2016) suggesting that we might gain further insight into the operation of shared environmental effects by undertaking a further multivariate analysis of these three syndromes. Therefore, in this study, we also apply a common factor model separately in males and females with the goal of understanding the sources of the shared environmental influences that are common to, versus unique to, DA, AUD, and $C B$, and the degree to which the pattern of results are similar or different in men and women.

\section{Methods}

As outlined previously for DA, AUD, and CB, we used linked data from multiple Swedish nationwide registries and healthcare data (Kendler, Ji et al., 2015; Kendler, Larsson Lönn et al., 2014; Kendler et al., 2012). Linking was achieved via the unique individual 10-digit personal identification number assigned at birth or immigration to all Swedish residents. To preserve confidentiality, this identification number was replaced by a serial number. We secured ethical approval for this study from the Regional Ethical Review Board of Lund University. For a definition of DA, AUD, and CB see Appendix A.

Among all individuals born in Sweden between 1960 and $1990(N=3,257,987)$ and alive at age 15 , we created seven datasets based on their genetic and geographical/household relationship. All analyses were stratified by gender, suggesting that we created $7 \times 2=14$ datasets. See Table 1 for a description of the datasets. AUD, CB, and DA were measured from age 15 until end of 2010 and were considered as binary variables in the models. For a definition of household and geographical status, see Appendix B.

\section{Statistical Analysis}

Our structural model divides the sources of individual differences in liability to DA, AUD, and $\mathrm{CB}$ into the following: additive genetic (A); four different components of the shared environment: close family (C_close), family (C_family), household (C_household), community (C_community); and unique environment (E). We extended the standard models used in twin research to include six variance sources for each phenotype. The four components of shared environment (C_close, C_family, C_household, C_community) are supposed to reflect different levels of the shared environment, ranging from close family experiences (C_close) to more distant community effects (C_community). In the models, we assumed that individuals within the same twin (MZ and DZ) and fullsibling (0-2 years apart - termed full-siblings 1) pairs share all forms of the environment - from close family experiences to community effects (C_close + C_family + 
TABLE 1

Description of Datasets and Assumptions for the Structural Equation Model

\begin{tabular}{|c|c|c|c|c|c|c|c|c|c|}
\hline \multirow[b]{2}{*}{ Sample name } & \multirow[b]{2}{*}{ Sample description } & \multicolumn{3}{|c|}{$\begin{array}{c}\text { Prevalence } \\
\text { (males/females) }\end{array}$} & \multirow{2}{*}{$\begin{array}{l}\text { Assumptions } \\
\text { for A } \\
\text { A* }^{*}\end{array}$} & \multicolumn{4}{|c|}{$\begin{array}{l}\text { Assumptions for } \mathrm{C} 1-\mathrm{C} 4 \text { in } \\
\text { the structural equation model }\end{array}$} \\
\hline & & $\mathrm{CB}$ & AUD & DA & & C_close & C_family & C_household & C_community \\
\hline SAMS ** & $\begin{array}{l}\text { Pairs residing in the same } \\
\text { SAMS at least } 6 \text { years until } \\
\text { age } 15, \text { maximum } 5 \text { years } \\
\text { age difference }(N= \\
249,000,000 \text { males and } \\
344,000,000 \text { females)) }\end{array}$ & $20.7 / 6.9$ & $5.5 / 2.4$ & $4.6 / 1.9$ & 0 & 0 & 0 & 0 & 1 \\
\hline Step-siblings & $\begin{array}{l}\text { Pairs residing in the same } \\
\text { household at least } 6 \text { years } \\
\text { until age } 15, \text { maximum } 5 \\
\text { years age difference }(N= \\
2,650 \text { males and } 2,039 \\
\text { females)) }\end{array}$ & 29.0/12.3 & 7.9/4.2 & $9.3 / 4.8$ & 0 & 0 & 0 & 1 & 1 \\
\hline Half-siblings & $\begin{array}{l}\text { Half-sibling pairs residing in } \\
\text { the same household }(\geq 1 \\
\text { year) until age } 15,3-10 \\
\text { years age difference }(N= \\
41,657 \text { males and } 38,751 \\
\text { females) }\end{array}$ & $31.3 / 12.3$ & $8.7 / 3.9$ & $10.5 / 4.3$ & 0.25 & 0 & 1 & 1 & 1 \\
\hline Full-siblings (2) & $\begin{array}{l}\text { Full-sibling pairs residing in } \\
\text { the same household }(\geq 1 \\
\text { year) until age } 15,3-10 \\
\text { years age difference }(N= \\
318,840 \text { males and } 286,856 \\
\text { females) }\end{array}$ & $16.6 / 5.9$ & $4.1 / 1.8$ & $4.1 / 1.7$ & 0.5 & 0 & 1 & 1 & 1 \\
\hline Full-siblings (1) & $\begin{array}{l}\text { Full-sibling pairs residing in } \\
\text { the same household at least } \\
12 \text { years until age } 15 \\
\text { maximum } 2 \text { years age } \\
\text { difference }(N=107,646 \\
\text { males and } 96,620 \text { females) }\end{array}$ & $18.5 / 6.7$ & $4.5 / 2.1$ & $5.0 / 2.0$ & 0.5 & 1 & 1 & 1 & 1 \\
\hline DZ twins & $\begin{array}{l}\text { Twin (DZ) pairs residing in the } \\
\text { same household at least } 12 \\
\text { years until age } 15(N= \\
2,281 \text { males and } 2,562 \\
\text { females) }\end{array}$ & $15.1 / 5.4$ & $3.7 / 1.7$ & $2.3 / 1.4$ & 0.5 & 1 & 1 & 1 & 1 \\
\hline$M Z$ twins & $\begin{array}{l}\text { Twin (MZ) pairs residing in the } \\
\text { same household at least } 12 \\
\text { years until age } 15 \text { ( } N= \\
2,589 \text { males and } 3,145 \\
\text { females) }\end{array}$ & $14.3 / 5.2$ & $3.0 / 2.8$ & $3.0 / 1.6$ & 1 & 1 & 1 & 1 & 1 \\
\hline
\end{tabular}

Note: ${ }^{*} \mathrm{~A}=$ additive genetics; $\mathrm{C}=$ shared environment. ${ }^{* *}$ SAMS $=$ Small area market statistics — there are approximately 9,200 SAMS throughout Sweden, their average population being around 1,000. Note that we could not model $249,00,000$ or 344,000,000 pairs in OpenMx. We therefore took a random sample of 500,000 pairs to be included in the models. The correlations were almost identical in the random sample as in the original sample.

C_household + C_community). This assumption is based on several empirical results from our prior analyses showing that, for these externalizing phenotypes, age differences in siblings are substantially and inversely correlated with resemblance (Kendler, Maes et al., 2013; Kendler, Morris et al., 2014; Kendler et al., 2012). These results suggest that twins and close-aged siblings share more of their rearing environment than do siblings further apart in age. For full- (termed full-siblings 2) and half-siblings more distant in age (3-10 years apart), but sharing the same household for at least part of their childhood, we assume that they share the same environment as twins and full-siblings close in age, except for the close family experiences (C_family + C_household + C_community). For step-siblings, we assume that they share the same household and community experiences (C_household + C_community). This assumption is based on results from our previous studies. Using the heritability estimate $\left(\mathrm{a}^{2}\right)$ for DA, CB, and AUD from our previous studies on those comparisons between pairs where the C_family component could easily be extracted (i.e., the comparison between full-siblings 2 and step-siblings as well as between halfsiblings and step-siblings), we see that 10 out of 12 comparisons indicate an extra environmental similarity between pairs that are genetically related (Kendler, Ohlsson et al., 2016). Furthermore, we assume that non-related individuals within the same SAMS only share the community effects (C_community). For all individuals residing in the same SAMS from at least 6 years until age 15 and with a maximum of 5 years' age difference, we created all possible pairs of non-related individuals. As it was not possible to model $249,000,000$ male or $344,000,000$ female pairs in OpenMx, we took a random sample of 500,000 male-male pairs and 500,000 female-female pairs to be included in the models. Unique environment (E) includes random developmental effects, environmental experiences not shared by 


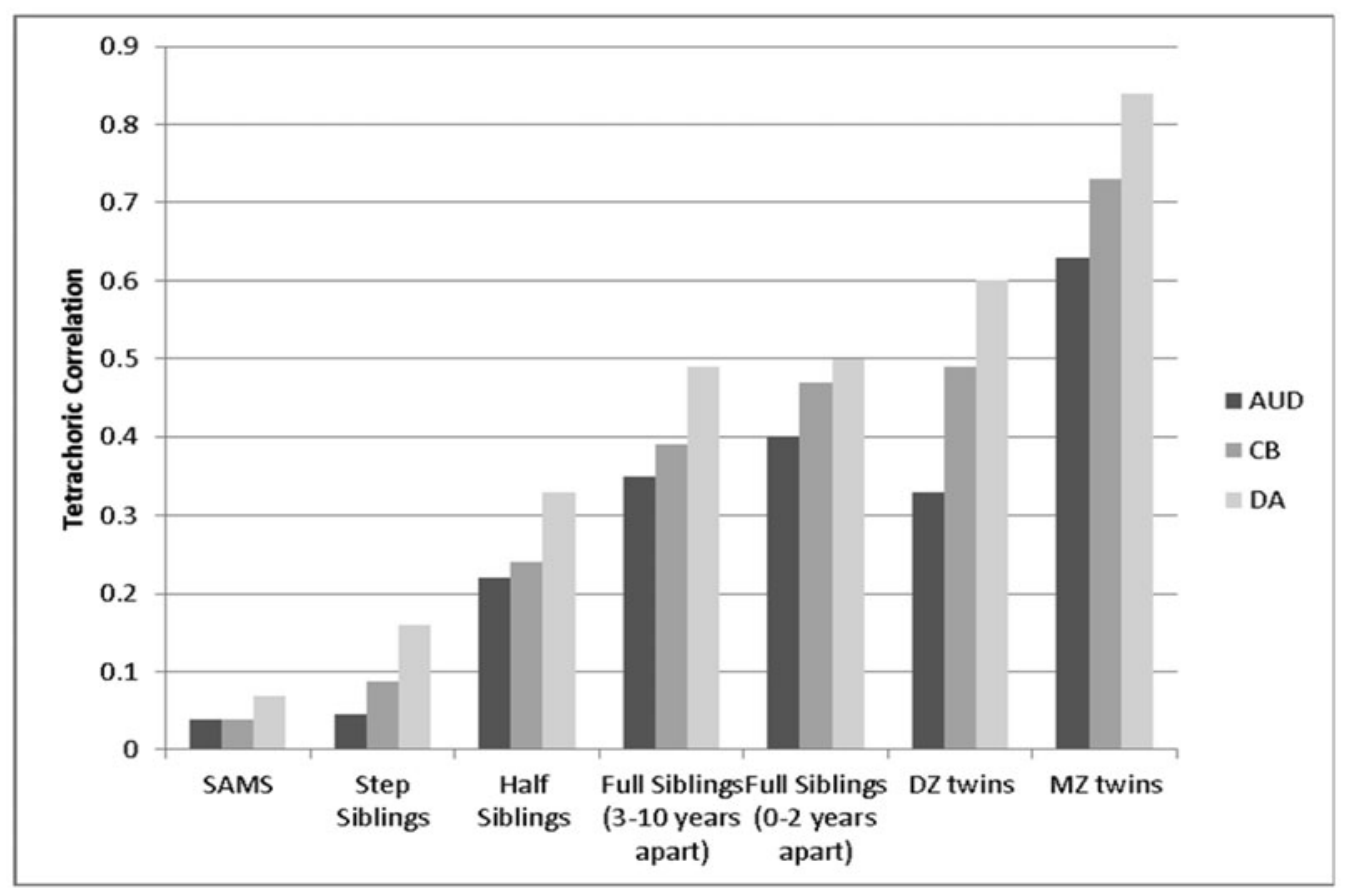

\section{FIGURE 1a}

Tetrachoric correlations within the different types of pairs (males). individuals within the different types of pairs, and random error.

In the next step, we wanted to investigate to what extent genetic and environmental factors are common for the three syndromes, with a particular focus on the different components of the shared environment. In the first model, an independent pathway model, we assumed that each of the six variance components (A, C_close, C_family, C_household, C_community, and E) consists of two parts: one that is common to all three phenotypes (denoted

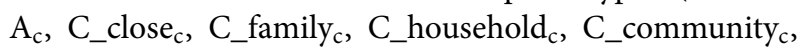
and $\left.E_{c}\right)$ and one that is specific to each one of them $\left(A_{s}\right.$, C_close $_{s}, C_{\text {ffamily }}$, C_household $_{s}, C_{\text {C_community }}$, and $\mathrm{E}_{\mathrm{s}}$ ). In the second model, a common pathway model, we assumed that the common variance components $\left(\mathrm{A}_{\mathrm{c}}\right.$, C_close $_{c}, C_{\text {ffamily }}$, C_household $_{c}, C_{\text {C_community }}$, and $\mathrm{E}_{\mathrm{c}}$ ) are mediated by a latent phenotype represented by a common factor (called 'externalizing behavior' in Figures 1 and 2). The common pathway model is nested within the independent pathway model. This latent phenotype mediates the common genetic and environmental effects, as the paths from $A_{c}, C_{-}$close $_{c}, C_{-}$family ${ }_{c}, C_{-}$household ${ }_{c}$, $\mathrm{C}_{-}$community $\mathrm{c}_{\mathrm{c}}$, and $\mathrm{E}_{\mathrm{c}}$ run via the latent phenotype.

Although our sample size is considerable, the models include many parameters and have limited statistical power. We therefore followed the recommendations based on simulations that showed that in such situations, parameter estimates from the full model are typically more accurate than those from sub-models even if the latter provides a better model fit (Sullivan \& Eaves, 2002). Unfortunately, we were not able to fit $95 \%$ confidence intervals for the parameters in the common pathway model. We therefore only present the standard errors for the estimated path coefficients in males only (see limitations section for further details). Models were fit in the OpenMx software (Neale et al., 2015).

\section{Results}

\section{Descriptive Findings Univariate Analyses}

The prevalence of registration for DA, AUD, and CB in our entire sample of Swedish males and females are seen in Table 1. CB was most common followed by AUD and DA. The prevalence of all three syndromes were considerably higher in the step-sibling and half-sibling groups, and lower in the twin groups, likely because the twins were screened for co-operativeness in having to return questionnaires about zygosity. For females, the full-siblings had lower prevalence. The overall prevalence in the entire population was $5.0 \%$ (DA), $4.6 \%$ (AUD), and $17.7 \%$ (CB) for males, and $2.1 \%, 2.0 \%$, and $6.5 \%$, respectively, for females.

The tetrachoric correlations within pairs for DA, AUD, and $\mathrm{CB}$ are seen in Figure 1a (males) and Figure $1 \mathrm{~b}$ (females). Focusing on males and the different $\mathrm{C}$ components, the following findings are noteworthy. First, the correlation among unrelated individuals within the same SAMS is above zero for all phenotypes, suggesting that parts of the shared environment could be attributed to community experiences. Second, the correlation among unrelated 


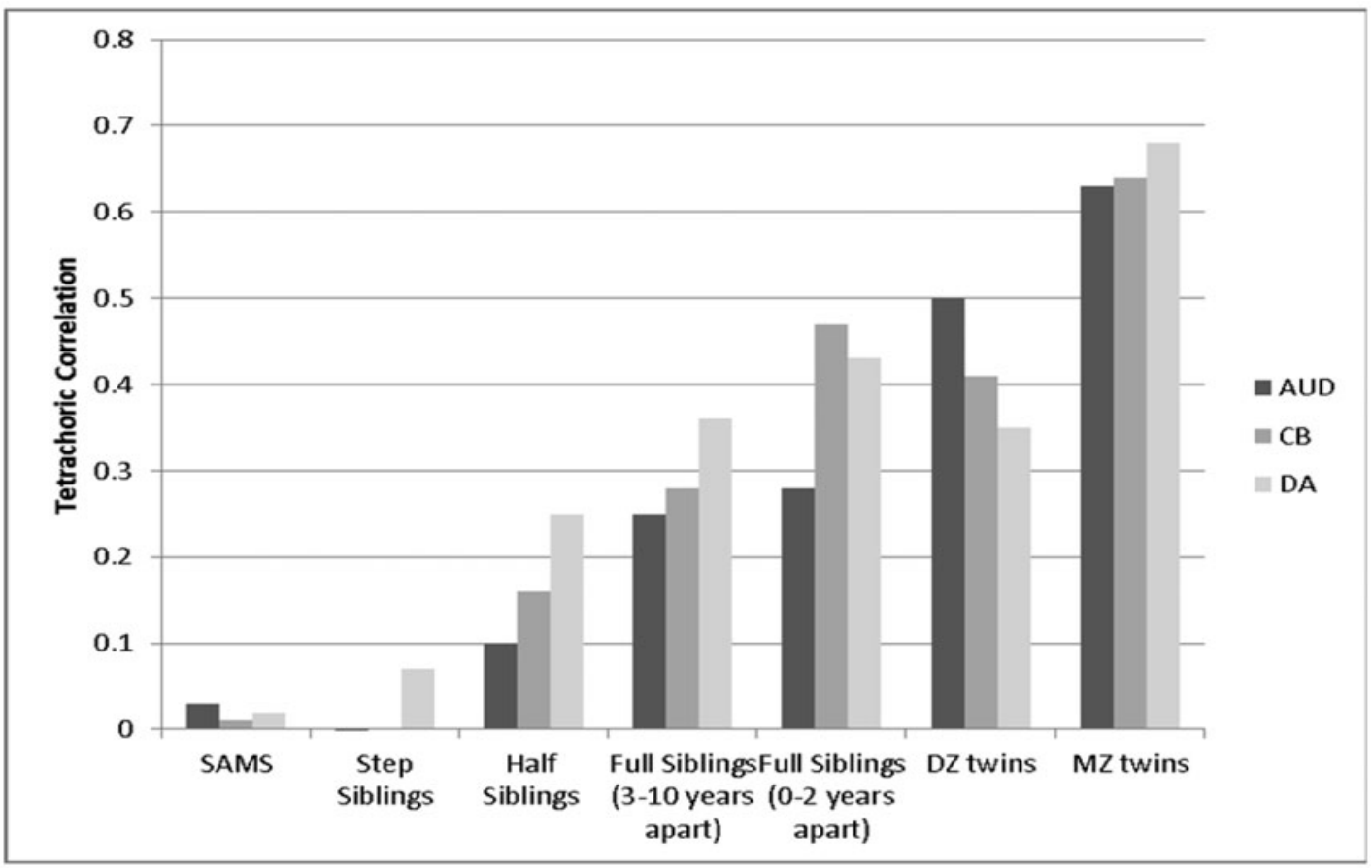

\section{FIGURE 1b}

Tetrachoric correlations within the different types of pairs (females).

individuals within the same household (step-siblings) is higher than the correlation among unrelated individuals within the same SAMS, suggesting that parts of the shared environment could be attributed to household experiences. Third, for AUD and CB, the correlation between full-sibling pairs close in age is higher than the correlation between full-sibling pairs further apart in age, giving evidence for a C_close component. Also, the DZ and full-sibling (close in age) correlation is more than half the $\mathrm{MZ}$ correlation, suggesting a total C effect (C_close + C_family + C_household + C_community) different from zero.

Focusing on females and the different $\mathrm{C}$ components, it is noteworthy that the correlation among unrelated individuals within the same SAMS is above zero for all phenotypes, but substantially lower than among males. Also, the within-household correlation (step-siblings) is low, and for $\mathrm{CB}$ and AUD actually lower than among individuals in the same SAMS, suggesting no appreciable household effect. On the other hand, the correlation between full-sibling pairs close in age is higher than the correlation between full-sibling pairs further apart in age, giving evidence for a C_close component. Also, except for AUD, the DZ and fullsibling (close in age) correlation is more than half the MZ correlation, suggesting a total C effect (C_close + C_family + C_household + C_community) different from zero.

\section{Model Fitting: Univariate Models}

In Table 2, the six variance components $\left(\mathrm{a}^{2}+\mathrm{c} \_\right.$close $^{2}+\mathrm{c}$ family ${ }^{2}+c$ household ${ }^{2}+c$ community ${ }^{2}+e^{2}$ ) for the three syndromes are shown for males. Focusing on shared environmental effects for DA, the C_community and C_household were most important, capturing more than $85 \%$ of the total effect of the shared environment. For CB and AUD, the patterns were different; the community and household captured less than $50 \%$ of the total effect of the shared environment, while the close family effect was more important. Note, however, that the $95 \%$ confidence intervals for the variance components are broad (except for the community effects). For females (Table 2), the pattern differed. For all syndromes, the $\mathrm{C}_{-}$close component was most important. For AUD and $\mathrm{CB}$, all the other $\mathrm{C}$ components were small. For DA, the $\mathrm{C}$ component increased as the nearness to the individual increased.

\section{Model Fitting: Multivariate Models}

We first fitted an independent pathway model, which resulted in a log-likelihood and AIC of 3110534 and 8589022 , respectively. The common pathway model, which included seven fewer parameters, had the following log likelihood and AIC: Likelihood: 3110392; estimated parameters 44; AIC: -8589076. The fit of the common pathway model was superior, and we therefore focused on the results from this model.

The parameter estimates for the four different $\mathrm{C}$ components as well as their loadings on the common latent factor for the common pathway model are seen in Figure 2a (males) and $2 \mathrm{~b}$ (females). The estimated total contributions of additive genetic, shared (four parts) and unique environ- 
TABLE 2

Variance Components from the Univariate Models

\begin{tabular}{llllllll}
\hline & A & C_close & C_family & C_household & C_community & E & AIC \\
\hline AUD (Males) & $51.8 \%[41.3,62.2]$ & $5.0 \%[0.0,7.3]$ & $4.8 \%[0.0,10.3]$ & $0.5 \%[0.0,9.0]$ & $3.9 \%[0.0,5.0]$ & $34.0 \%[28.7,39.5]$ & -3128064 \\
DA (Males) & $65.3 \%[56.8,73.2]$ & $1.4 \%[0.0,3.4]$ & $1.4 \%[0.0,11.3]$ & $6.7 \%[0.0,11.8]$ & $8.3 \%[7.0,9.4]$ & $17.0 \%[12.9,21.4]$ & -3174048 \\
CB (Males) & $58.5 \%[53.1,63.7]$ & $7.7 \%[6.5,8.9]$ & $1.3 \%[0.0,7.8]$ & $4.7 \%[0.0,8.2]$ & $3.9 \%[3.4,4.5]$ & $23.9 \%[21.2,26.6]$ & -2005214 \\
AUD (Females) & $45.1 \%[37.0,51.2]$ & $3.6 \%[0.0,7.8]$ & $0.0 \%[0.0,3.3]$ & $0.0 \%[0.0,4.3]$ & $2.7 \%[0.0,4.6]$ & $48.6 \%[44.1,53.2]$ & -3316275 \\
DA (Females) & $45.0 \%[32.6,60.0]$ & $7.3 \%[0.0,11.0]$ & $6.9 \%[0.0,18.6]$ & $4.5 \%[0.0,17.1]$ & $1.8 \%[0.0,4.2]$ & $34.4 \%[26.8,42.3]$ & -3356165 \\
CB (Females) & $51.6 \%[42.3,57.5]$ & $5.5 \%[0.0,7.6]$ & $1.5 \%[0.0,6.0]$ & $0.0 \%[0.0,5.2]$ & $1.2 \%[0.0,2.2]$ & $40.2 \%[36.6,45.0]$ & -2794358 \\
\hline
\end{tabular}

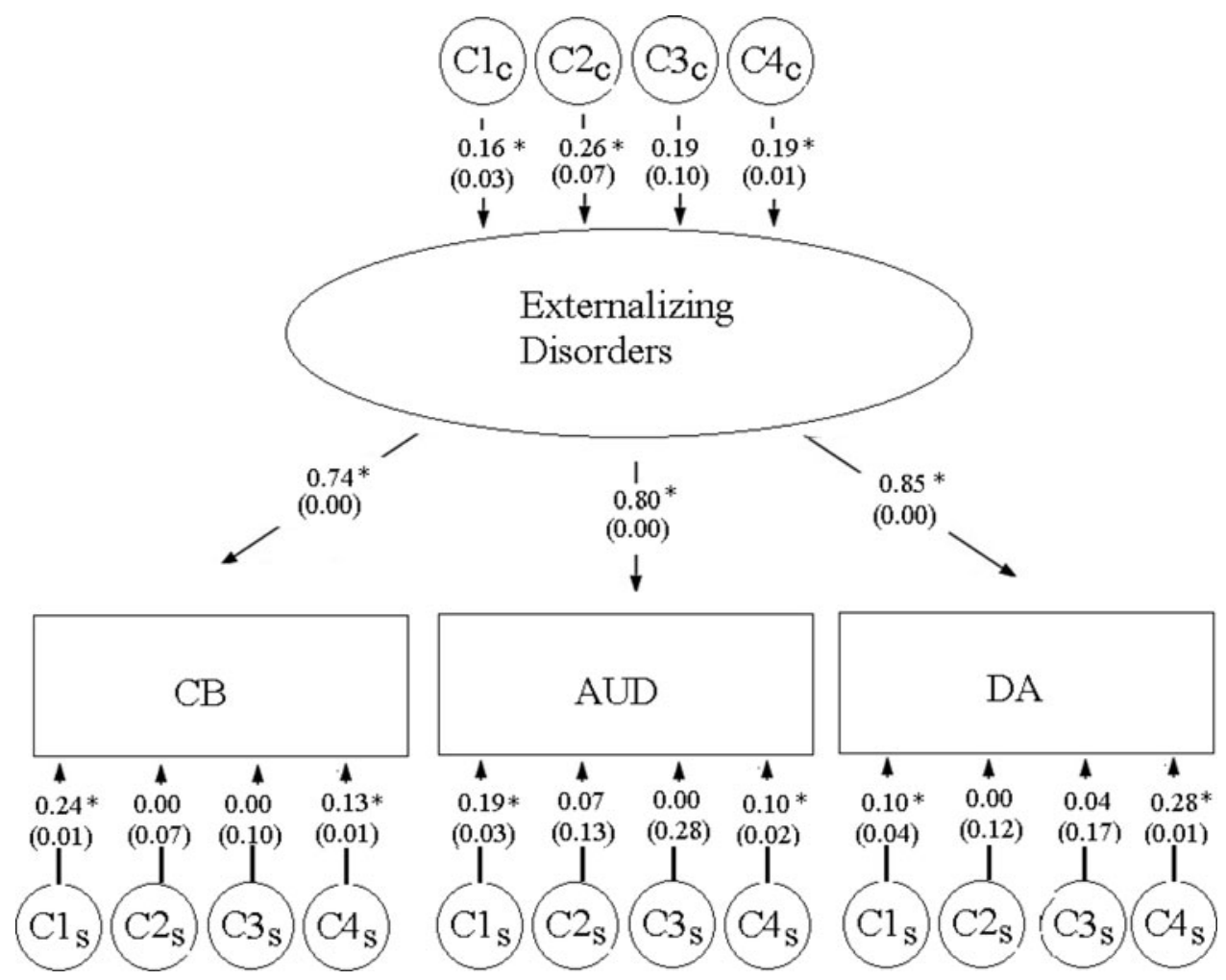

\section{FIGURE 2a}

Parameter estimates and standard errors for the four $\mathrm{C}$ components from the best fit common pathway model (males). Note: $\mathrm{C} 1$ = C_close; C2 = C_family; C3 = C_household; and C4 = C_community. Paths are standardized partial regression coefficients. ${ }^{*}$ Suggest that the path is statistically significant at the $5 \%$ level.

mental effects on the three forms of externalizing behaviors, and the proportion of each that is common versus specific in its effect are seen in Table $3 \mathrm{a}$ (males) and $3 \mathrm{~b}$ (females).

\section{Males}

First, all behaviors loaded quite strongly on the common factor, with the loading for DA $(+0.85)$ being slightly higher than that seen for AUD $(+0.80)$ and $\mathrm{CB}(+0.74)$. Similar to but somewhat more pronounced than with the univariate model, estimates for total shared environmental contributions (C_close + C_family + C_household + C_community) were higher for DA than for AUD and CB (c_close ${ }^{2}+$ c family ${ }^{2}+$ c household ${ }^{2}+$ community $^{2}=$ 0.21 [DA]; 0.17 [CB]; and 0.16 [AUD]). Also similar to the univariate models, among the four components of C, community experiences were most important for DA (c_community ${ }^{2}=0.10$ ), while for $\mathrm{CB}$ and AUD, the close family environment were of more importance (c_close ${ }^{2}$ $=0.08[\mathrm{CB}]$ and $\mathrm{c}_{-}$close $\left.^{2}=0.05[\mathrm{AUD}]\right)$. More similar estimates, and also more modest, were seen across syndromes for the two $\mathrm{c}$ components in between community experiences and close family experiences (c_family, c_household). This was slightly different from what was seen in the univariate models. Third, syndrome-specific community effects were mainly seen for DA and partly for $\mathrm{CB}$, while syndrome-specific close family effects were mainly seen for AUD and CB. The two C components in between community experiences and close family experiences (c_family, c_household) were estimated to almost entirely derive from the common latent factor. Note that for all syndromes, the effect of additive genetics was 2-4 times the size of the total shared environmental effect. 


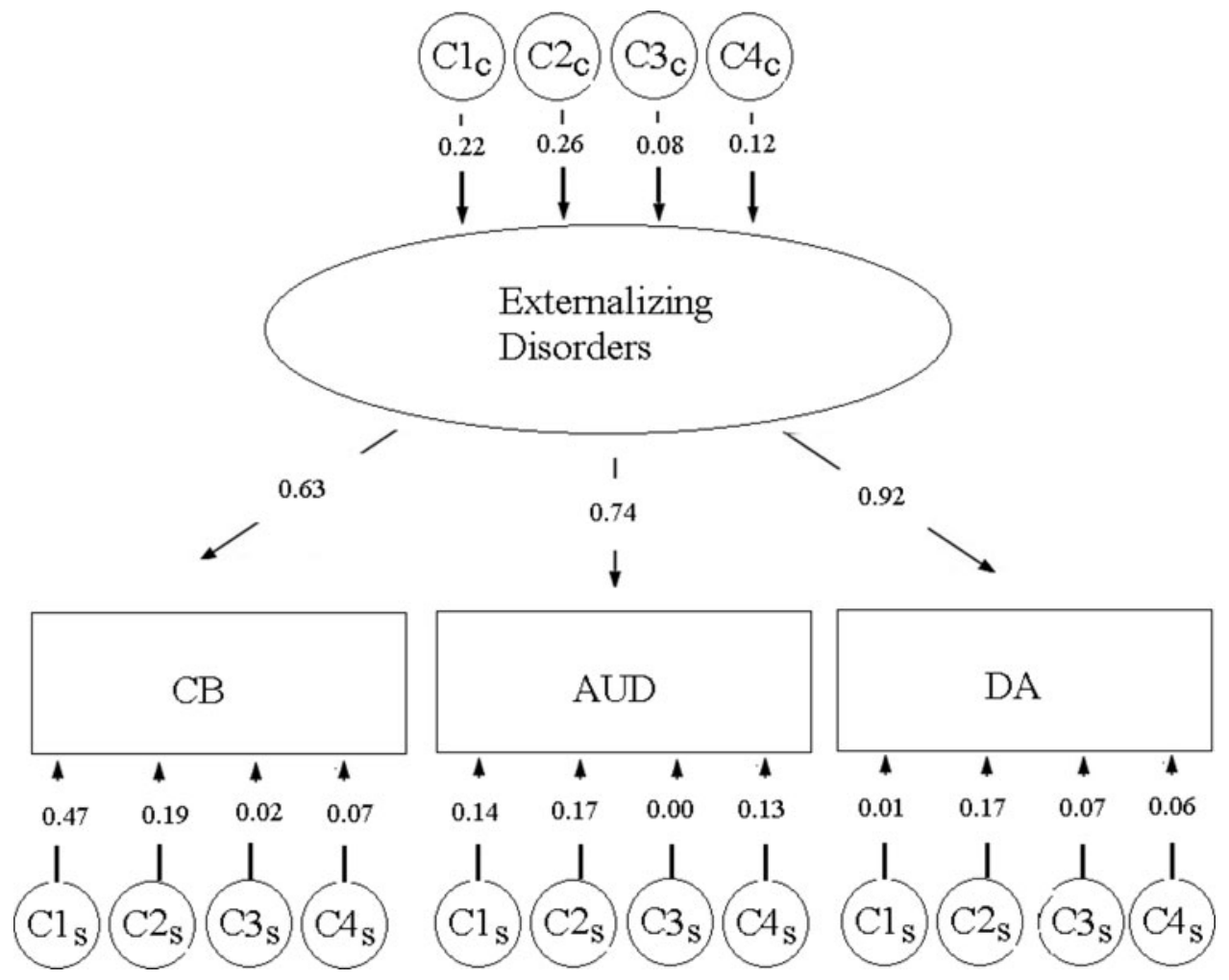

\section{FIGURE 2b}

Parameter estimates and standard errors for the four $\mathrm{C}$ components from the best fit common pathway model (females). Note: $\mathrm{C} 1=$ C_close; C2 = C_family; C3 = C_household; and C4 = C_community. Paths are standardized partial regression coefficients.

\section{Females}

As for males, we first fitted an independent pathway model that resulted in a log-likelihood and AIC of 1554073 and 9569501, respectively. The common pathway model had a lower AIC (-9569773) and we therefore focused on the results from this model.

All behaviors loaded strongly on the common factor, but the loading for DA $(+0.92)$ was substantially higher than that seen for CB $(+0.63)$ and AUD $(+0.74)$. Second, as seen in the univariate models, estimates for total shared environmental contributions (C_close + C_family + C_household + C_community) were substantially lower than for males. They were higher for DA $\left(c \_c l o s e^{2}+c\right.$ family $^{2}+$ chousehold $^{2}+c$ community $^{2}=0.18$ [DA] than for either CB [0.10] or AUD [0.14]). Among the four components of $\mathrm{c}$, the community experiences was just slightly above zero while the c components referred to as the household effect were almost zero. The total close family experiences were similar and most important across syndromes and also divided into common and specific components. For c_family, the total effect was strongest for DA (0.09) and it was only for DA that there was a syndrome specific effect of c_family. For all syndromes, the effects of additive genetic factors were 2-4 times the size of the total effect of the shared environment.

\section{Discussion}

We sought in these analyses, using information available to us from a range of Swedish national registries, to subdivide the latent concept of 'shared environment' or $\mathrm{C}$ into four subcomponents that we termed (1) close family, (2) family, (3) household, and (4) community. We applied our model to three externalizing syndromes that we had previously studied and for which we had detected substantial evidence for shared environment. We first fitted univariate models and then a common pathway model to males and females separately, which permitted us to determine the degree to which these $\mathrm{C}$ sub-components were common across the three syndromes versus syndrome specific and were similar in magnitude in males and females.

Examining first the influences common to all three externalizing syndromes, in both males and females, all the shared environmental components had only modest effects. But among them, in males, family environment had the largest effect, followed by household and community with close family effects being the weakest. The pattern was different in females. Family effects remained the strongest but was then followed by close family with household and community effects being considerably weaker. 


\section{TABLE 3a}

Variance Components from the Best-Fitting Model (Males)

\begin{tabular}{llll}
\hline & CB & AUD & DA \\
\hline A (Additive genetics) & $\mathbf{5 7 . 7} \%$ & $\mathbf{5 1 . 0} \%$ & $\mathbf{6 2 . 9 \%}$ \\
\% Common & $71 \%$ & $94 \%$ & $86 \%$ \\
\% Specific & $29 \%$ & $6 \%$ & $14 \%$ \\
C_close & $7.5 \%$ & $5.3 \%$ & $2.9 \%$ \\
\% Common & $20 \%$ & $32 \%$ & $66 \%$ \\
$\%$ Specific & $80 \%$ & $68 \%$ & $34 \%$ \\
C_family & $3.8 \%$ & $4.8 \%$ & $5.0 \%$ \\
\% Common & $100 \%$ & $92 \%$ & $100 \%$ \\
$\%$ Specific & $0 \%$ & $8 \%$ & $0 \%$ \\
C_household & $2.0 \%$ & $2.3 \%$ & $2.8 \%$ \\
$\%$ Common & $100 \%$ & $100 \%$ & $93 \%$ \\
\% Specific & $0 \%$ & $0 \%$ & $7 \%$ \\
C_community & $3.6 \%$ & $3.2 \%$ & $10.4 \%$ \\
$\%$ Common & $53 \%$ & $69 \%$ & $24 \%$ \\
\% Specific & $47 \%$ & $31 \%$ & $76 \%$ \\
E (Unique environment) & $25.4 \%$ & $33.3 \%$ & $16.2 \%$ \\
\% Common & $18 \%$ & $16 \%$ & $37 \%$ \\
\% Specific & $82 \%$ & $84 \%$ & $63 \%$ \\
\hline
\end{tabular}

With regard to syndrome-specific, shared environmental effects, in males, family and household effects were consistently either absent or very small in magnitude. By contrast, close family effects were relatively strong for $\mathrm{CB}$ and AUD, and weaker for DA. However, community effects were relatively strong for DA and weaker for CB and AUD. The pattern was different in women. By far the strongest impact was seen for close family effects specific to $\mathrm{CB}$, followed by family effects also for $\mathrm{CB}$. Family effects also impacted modestly on AUD and DA with all other effects being quite small in magnitude.

These patterns were similar in the univariate models. However, as seen from the univariate models, where confidence intervals could be estimated, the uncertainty of the estimates for the different $\mathrm{C}$ components was rather high.

These results are broadly consistent with several prior results we have obtained for Swedish samples using different analytic methods. First, congruent with our current findings, in a prior traditional common pathway twin analysis of DA, CB, and AUD (Kendler, Lonn et al., 2016), we found shared environmental influences on the common liability and specific liabilities to $\mathrm{CB}$ and $\mathrm{DA}$ to be considerably stronger in males than females. Second, using multilevel modeling controlling for familial factors, we found that community level influences had a considerably stronger influence on DA in males than females (Kendler, Ohlsson et al., 2015). We found exactly this pattern for our DA-specific community effects in these analyses. Third, using conditional logistic models, resemblance in male and female sibling pairs for both DA (Kendler, Ohlsson et al., 2013) and CB (Kendler, Morris et al., 2014) were greater for those closer versus more distant in age. These results reflect what we would here call our 'close family' effects - biological sibling pairs of close age raised together - that we see to be especially prominently for $\mathrm{CB}$ in these analyses. Fourth, using Cox proportional hazard regression models, we found

\section{TABLE 3b}

Variance Components from the Best-Fitting Model (Females)

\begin{tabular}{llll}
\hline & CB & AUD & DA \\
\hline A (Additive genetics) & $47.9 \%$ & $36.9 \%$ & $54.9 \%$ \\
\% Common & $53 \%$ & $95 \%$ & $100 \%$ \\
\% Specific & $47 \%$ & $5 \%$ & $0 \%$ \\
C_close & $5.5 \%$ & $5.5 \%$ & $7.0 \%$ \\
\% Common & $35 \%$ & $47 \%$ & $57 \%$ \\
\% Specific & $65 \%$ & $53 \%$ & $43 \%$ \\
C_family & $2.7 \%$ & $3.7 \%$ & $8.9 \%$ \\
\% Common & $100 \%$ & $100 \%$ & $66 \%$ \\
\% Specific & $0 \%$ & $0 \%$ & $34 \%$ \\
C_household & $0.3 \%$ & $0.3 \%$ & $0.9 \%$ \\
$\%$ Common & $100 \%$ & $100 \%$ & $44 \%$ \\
\% Specific & $0 \%$ & $0 \%$ & $56 \%$ \\
C_community & $1.1 \%$ & $2.6 \%$ & $1.7 \%$ \\
\% Common & $55 \%$ & $31 \%$ & $76 \%$ \\
\% Specific & $45 \%$ & $69 \%$ & $24 \%$ \\
E (Unique environment) & $42.7 \%$ & $51.0 \%$ & $29.5 \%$ \\
$\%$ Common & $20 \%$ & $23 \%$ & $63 \%$ \\
\% Specific & $80 \%$ & $77 \%$ & $37 \%$ \\
\hline
\end{tabular}

in male and female sib-pairs that the syndromes of both DA and $\mathrm{CB}$ were 'transmitted' considerably more strongly from older to younger than younger to older siblings (Kendler, Morris et al., 2014; Kendler, Ohlsson et al., 2013). In our current conceptual framework, these effects would likely be reflected in both 'close family' and 'family' effects. Fifth, we found in male-male full- and half-sibling pairs resemblance in risk for DA was predicted by years of living together in the same household (Kendler, Maes et al., 2013). These results would also reflect what we call close family and family effects. These same analyses found slightly weaker but significant effects on pair resemblance for years of residing in the same community but not the same household - what we would here call community effects (Kendler, Maes et al., 2013). Finally, congruent with our findings, we examined the same two effects in female-female half- and full-sibling pairs and found that they were present but weaker than those observed in the male-male pairs (Kendler, Maes et al., 2013). Our results are also consistent with findings from Burt et al. (2015), who sampled communities across Michigan and found that $11 \%$ of the population variance in selfreported non-aggressive rule-breaking - a broad index of an externalizing predisposition - was predicated from the participant's neighborhood.

We found that community effects on externalizing syndromes, especially DA, were larger in males than females. This is consistent with evidence that compared to females, males are more motivated to use psychoactive substances to conform to subgroup values and are more peer influenced in their intake of drugs (Borsari \& Carey, 2001; Graziano et al., 2012). In a relevant Swedish high-school student survey, Svensson (2003) found that males compared to females had higher exposure rates to deviant peers. This arose because parents of girls compared to parents of boys monitored their behavior and friends more closely and that the probability of drug use was more strongly predicted by peer deviance in males than in females (Svensson, 2003). 
Our results are at the latent level and so do not illuminate the more specific social mechanisms through which our components of shared environment actually impact on resemblance in relatives. A few speculations, however, are in order. First, we suspect that the close family effects are likely driven largely through peer effects. Close-aged siblings are much more likely to socialize together and share peer groups than are siblings distant in age with one another. It would also be likely that close-aged siblings would use drugs or alcohol together or one would provide the substance (i.e., 'turn on') the other. For CB, close-age siblings are more likely to collaborate in criminal activity, which might be responsible for the substantial close familyspecific effects for CB in our analyses. Second, we suspect that family effects for externalizing syndromes likely reflect parental characteristics that have broadly consistent effects across all of their offspring including SES, parenting styles, and levels of parental monitoring, all of which have been shown to impact on risk for externalizing syndromes in children (Bleuler, 1955; Farrington, 2005; Hawkins et al., 1998; Kendler et al., 2000; Otowa et al., 2013). Third, our distinction between family and household effects was perhaps the most speculative part of our model. This was meant to capture the difference between biological and step-siblings living in the same household with the expectation that biological siblings would experience more similar environments. Our analyses provided some evidence that our hypothesis was correct. Fourth, community effects could result from differences in the general peer environment in the community and particularly in the schools and the degree to which deviant behaviors in adolescence were encouraged. For example, a study in nearby Finland documented substantially different rates of smoking and drinking in different schools (Rose et al., 2003). For DA, an additional potentially important feature of community effects is likely availability and price of illicit substances, which might be driving the DA-specific community effects.

In summary, in line with recent reviews by Burt (2009, 2014), our results confirm both the overall importance of the shared environment for broadly defined psychopathology and the potential progress that can be made in understanding the nature of these influences by decomposing $\mathrm{c}^{2}$ into its constituent parts.

\section{Limitations}

These results should be interpreted in the context of several potential methodological limitations. First, optimization issues in OpenMx made it infeasible to obtain confidence intervals for the parameter estimates in the common pathway model. Still, for males, we presented standard errors of the path coefficients. For females, we encountered problems in finding the global likelihood maximum. Focusing on finding the best fit for the models, we ran each model from a variety of starting values, and reran them from the previously fitted values, to ensure that a global likelihood maximum had been reached. This made the standard errors for some parameters unreliable; hence, we did not report them. Note, however, that we are using complete population data; consequently, the precision of the estimates cannot be improved. Second, the definition and the assumptions in the models for the four $\mathrm{C}$ components in the model could be questioned. The geographical boundaries of the SAMS, while generally set to reflect natural community boundaries, were set for administrative reasons. It is possible that other criteria, such as municipalities, school districts, or geographic units centered on individuals' residences, might have done a superior job of capturing community-level influences. Despite these shortcomings, the SAMS units have previously been used successfully to capture a collective influence and, as seen here particularly for males, it also captures a substantial collective influence. While the household is a clearly defined unit, the separation between close family (C1) and family (C2) could be questioned. However, for all six within-syndrome correlations, the full-siblings closer in age had a higher correlation than full-siblings further apart in age. Also, we did not include a T parameter in the model, which would capture the difference between close-in-age full-siblings and DZ pairs. Nevertheless, comparing the correlations between DZ pairs and full-sibling pairs do not support a $\mathrm{T}$ effect as for three out of six within-syndromes correlations the full-sibling correlation were higher than the DZ correlations. Third, we defined the shared environments as any environmental, that is, non-genetic, influence that increases similarity regardless of the proportion of genes shared. Hence, we then assume that pairs do not create or provoke more similar environments for themselves because they are more similar genetically. However, for household, we allowed for a difference between biological and step-siblings living in the same household with the expectation that biological siblings would experience more similar environments. We did not allow this for the community effect (C4). We partly tested this by only analyzing non-related individuals and estimated a model with only the household (C3) and the community (C4) effect. The community effect (measured as the share of total variance) was identical over the two models. Fourth, we used several different registers to construct the three syndromes, and the time frame during which data for $\mathrm{CB}, \mathrm{AUD}$, and DA are available is different for different registries, which might explain why full-siblings and half-siblings further apart in age are less similar. However, the difference in the withinsyndrome correlations when comparing full-siblings close in age and full-siblings further apart in age is similar when we investigate those born 1980-1990 and are exposed during the period when we have the most information from all registers included. Fifth, while using registry data has the important advantage of not requiring accurate respondent recall and reporting, the risk for time-dependent bias due to registry effects remains. In addition, only a subset of individuals who are drug abusers (or alcohol abusers) 
would ever require medical treatment or commit an alcohol or drug-related crime, which means that our registries alone do not capture the true prevalence in the population. However, such data likely contains both false negative and false positive diagnoses, the frequency of which we cannot estimate.

\section{Acknowledgments}

This project was supported by the grants R01AA023534 and F32AA02226 from the National Institute of Alcohol Abuse and Alcoholism, the Swedish Research Council (K2012-70X-15428-08-3), the Swedish Research Council for Health, Working Life, and Welfare (In Swedish: Forte; Reg.nr: 2013-1836), the Swedish Research Council (20122378; 2014-10134) and FORTE (2014-0804) as well as ALF funding from Region Skåne awarded. None of the authors have any conflicts of interest to report.

\section{Ethical Standards}

The authors assert that all procedures contributing to this work comply with the ethical standards of the relevant national and institutional committees on human experimentation and with the Helsinki Declaration of 1975, as revised in 2008. We secured ethical approval for this study from the Regional Ethical Review Board of Lund University (No. 2008/409).

\section{References}

Bleuler, M. (1955). Familial and personal background of chronic alcoholics. In O. Diethelm (Ed.), Etiology of chronic alcoholism (pp. 110-166). New York, NY: Charles C. Thomas.

Borsari, B., \& Carey, K. B. (2001). Peer influences on college drinking: A review of the research. Journal of Substance Abuse, 13, 391-424.

Burt, S. A. (2009). Rethinking environmental contributions to child and adolescent psychopathology: A meta-analysis of shared environmental influences. Psychological Bulletin, 135, 608-637.

Burt, S. A. (2014). Research review: The shared environment as a key source of variability in child and adolescent psychopathology. Journal of Child Psychology and Psychiatry, $55,304-312$.

Burt, S. A., Klump, K. L., Kashy, D. A., Gorman-Smith, D., \& Neiderhiser, J. M. (2015). Neighborhood as a predictor of non-aggressive, but not aggressive, antisocial behaviors in adulthood. Psychological Medicine, 45, 2897-2907.

Falconer, D. S. (1989). Introduction to quantitative genetics (3rd ed.). New York, NY: Wiley.

Farrington, D. (2005). Childhood origins of antisocial behavior. Clinical Psychology and Psychotherapy, 12, 177-190.

Graziano, F., Bina, M., Giannotta, F., \& Ciairano, S. (2012). Drinking motives and alcoholic beverage preferences among Italian adolescents. Journal of Adolescence, 35, 823831.
Hawkins, J. D., Herrenkohl, T., Farrington, D. P., Brewer, D., Catalano, R. F., \& Harachi, T. W. (1998). A review of predictors of youth violence. In R. Loeber \& D. P. Farrington (Eds.), Serious and violent juvenile offenders: Risk factors and successful interventions (pp. 106-146). London, UK: Sage Publications.

Kendler, K. S., Jacobson, K. C., Prescott, C. A., \& Neale, M. C. (2003). Specificity of genetic and environmental risk factors for use and abuse/dependence of cannabis, cocaine, hallucinogens, sedatives, stimulants, and opiates in male twins. American Journal of Psychiatry, 160, 687-695.

Kendler, K. S., Ji, J., Edwards, A. C., Ohlsson, H., Sundquist, J., \& Sundquist, K. (2015). An extended Swedish national adoption study of alcohol use disorder. JAMA Psychiatry, 72, 211-218.

Kendler, K. S., Larsson Lönn, S., Morris, N. A., Sundquist, J., Långström, N., \& Sundquist, K. (2014). A Swedish national adoption study of criminality. Psychological Medicine, 44, 1913-1925.

Kendler, K. S., Lonn, S. L., Maes, H. H., Lichtenstein, P., Sundquist, J., \& Sundquist, K. (2016). A Swedish population-based multivariate twin study of externalizing disorders. Behavior Genetics, 46, 183-192.

Kendler, K. S., Maes, H. H., Lönn, S. L., Morris, N. A., Lichtenstein, P., Sundquist, J., \& Sundquist, K. (2015). A Swedish national twin study of criminal behavior and its violent, white-collar and property subtypes. Psychological Medicine, 45, 2253-2262.

Kendler, K. S., Maes, H. H., Sundquist, K., Ohlsson, H., \& Sundquist, J. (2013). Genetic and family and community environmental effects on drug abuse in adolescence: A Swedish national twin and sibling study. American Journal of Psychiatry, 171, 209-217.

Kendler, K. S., Morris, N. A., Lönn, S. L., Sundquist, J., \& Sundquist, K. (2014). Environmental transmission of violent criminal behavior in siblings: A Swedish national study. Psychological Medicine, 44, 3181-3187.

Kendler, K. S., Myers, J., \& Prescott, C. A. (2000). Parenting and adult mood, anxiety and substance use disorders in female twins: An epidemiological, multi-informant, retrospective study. Psychological Medicine, 30, 281-294.

Kendler, K. S., Ohlsson, H., Edwards, A. C., Lichtenstein, P., Sundquist, K., \& Sundquist, J. (2016). A novel siblingbased design to quantify genetic and shared environmental effects: Application to drug abuse, alcohol use disorder and criminal behavior. Psychological Medicine, 46, 16391650.

Kendler, K. S., Ohlsson, H., Sundquist, K., \& Sundquist, J. (2013). Within-family environmental transmission of drug abuse: A Swedish national study. JAMA Psychiatry, 70, 235242.

Kendler, K. S., Ohlsson, H., Sundquist, K., \& Sundquist, J. (2015). Environmental clustering of drug abuse in households and communities: Multi-level modeling of a national Swedish sample. Social Psychiatry and Psychiatric Epidemiology, 50, 1277-1284.

Kendler, K. S., Prescott, C. A., Neale, M. C., \& Pedersen, N. L. (1997). Temperance board registration for alcohol abuse in 
a national sample of Swedish male twins, born 1902 to 1949. Archives of General Psychiatry, 54, 178-184.

Kendler, K. S., Sundquist, K., Ohlsson, H., Palmer, K., Maes, H., Winkleby, M. A., \& Sundquist, J. (2012). Genetic and familial environmental influences on the risk for drug abuse: A national Swedish adoption study. Archives of General Psychiatry, 69, 690-697.

Lee, S. H., DeCandia, T. R., Ripke, S., Yang, J., Sullivan, P. F., Goddard, M. E., ... Wray, N. R. (2012). Estimating the proportion of variation in susceptibility to schizophrenia captured by common SNPs. Nature Genetics, 44, 247-250.

Lynch, M., \& Walsh, B. (1998). Genetics and analysis of quantitative traits. Sunderland, MA: Sinauer Associates.

Mather, K., \& Jinks, J. L. (1982). Biometrical genetics: The study of continuous variation (3rd ed.) London, UK: Chapman \& Hall.

McGue, M., Pickens, R. W., \& Svikis, D. S. (1992). Sex and age effects on the inheritance of alcohol problems: A twin study. Journal of Abnormal Psychology, 101, 3-17.

Neale, M. C., Hunter, M. D., Pritikin, J. N., Zahery, M., Brick, T. R., Kirkpatrick, R. M., ... Boker, S. M. (2015) OpenMx 2.0: Extended Structural Equation and Statistical Modeling. Psychometrika Jan 27([epub]).

Otowa, T., Gardner, C. O., Kendler, K. S., \& Hettema, J. M. (2013). Parenting and risk for mood, anxiety and substance use disorders: A study in population-based male twins. Social Psychiatry and Psychiatric Epidemiology, 48, 1841-1849.

Plomin, R., \& Daniels, D. (1987). Why are children in the same family so different for one another? Behavioral and Brain Sciences, 10, 1-60.

Purcell, S. M., Moran, J. L., Fromer, M., Ruderfer, D., Solovieff, N., Roussos, P., ... Sklar, P. (2014). A polygenic burden of rare disruptive mutations in schizophrenia. Nature, 506, 185-190.

Purcell, S. M., Wray, N. R., Stone, J. L., Visscher, P. M., O'Donovan, M. C., Sullivan, P. F., ... Scolnick, E. M. (2009). Common polygenic variation contributes to risk of schizophrenia and bipolar disorder. Nature, 460, 748-752.

Rhee, S. H., \& Waldman, I. D. (2002). Genetic and environmental influences on antisocial behavior: A meta- analysis of twin and adoption studies. Psychological Bulletin, 128, 490-529.

Rose, R. J., Viken, R. J., Dick, D. M., Bates, J. E., Pulkkinen, L., \& Kaprio, J. (2003). It does take a village: Nonfamilial environments and children's behavior. Psychological Science, 14, 273-277.

Sullivan, P. F., \& Eaves, L. J. (2002). Evaluation of analyses of univariate discrete twin data. Behavior Genetics, 32, 221227.

Svensson, R. (2003). Gender differences in adolescent drug use - The impact of parental monitoring and peer deviance. Youth \& Society, 34, 300-329.

Truett, K. R., Eaves, L. J., Walters, E. E., Heath, A. C., Hewitt, J. K., Meyer, J. M., ... Kendler, K. S. (1994). A model system for analysis of family resemblance in extended kinships of twins. Behavior Genetics, 24, 35-49.
Verhulst, B., Neale, M. C., \& Kendler, K. S. (2015). The heritability of alcohol use disorders: A meta-analysis of twin and adoption studies. Psychological Medicine, 45, 10611072.

\section{Appendix A}

DA was identified in the Swedish medical (the Swedish Hospital Discharge Register, containing all hospitalizations for all Swedish inhabitants from 1973-2010 and the Outpatient Care Register, containing information from outpatient clinics from 2001 to 2010) and mortality registries by ICD codes (ICD-8: drug dependence [304]; ICD-9: drug-induced psychoses [292] and drug dependence [304]; ICD-10: mental and behavioral disorders due to psychoactive substance use [F10-F19], except those due to alcohol [F10] or tobacco [F17]); in the Suspicion Register, which records arrests by codes 3070 (driving under the influence of drugs), 5010 (drug possession), 5011 (drug use), and 5012 (possession and use), which reflect crimes related to drug abuse; and in the Crime Register, which reflects convictions by references to laws covering narcotics (law 1968:64, paragraph 1, point 6) and drug-related driving offenses (law 1951:649, paragraph 4, subsection 2 and paragraph 4A, subsection 2). Drug abuse was identified in individuals (excluding cancer patients) in the Prescribed Drug Register who had filled prescriptions of hypnotics and sedatives (Anatomical Therapeutic Chemical [ATC] Classification System N05C and N05BA) or opioids (ATC: N02A) in dosages consistent with drug abuse, that is, on average more than four defined daily doses a day for 12 months.

CB was defined from the Swedish Crime Register based on the following convictions, law and chapter in parentheses: (aggravated) assault $(3: 5,3: 6)$; illegal threat (4:5); threats and violence against an officer (17:1, 17:2); intimidation (4:7); (Gross) violation of a person's/woman's integrity (4:4a); kidnapping $(4: 1)$; illegal confinement or restraint (4:2); (aggravated) robbery (8:5, 8:6); illegal coercion (4:4); (aggravated) Arson (13:1, 13:2); murder, manslaughter or filicide (3:1, 3:2, 3:3); sexual crimes (excluding prostitution and the buying of sexual services but including child pornography) (6:1-6:10, 6:12, 16:10A); theft of a vehicle (8:1-2, 8:4, 8:7-8); theft (including burglary) (8:1-2, 8:4); vandalism (12:1-4); vandalism causing danger to the public, sabotage, hijacking (13:3-10 (5a-b)); unlawful entering of a person's home, trespassing (4:6); fraud (9:1-10); embezzlement (10:1-8 (5a-e)); dishonesty/crime towards a creditor (includes forged book-keeping in companies) (11:1-5); and forgery (14:1-10); and thereby excluding convictions for minor crimes like traffic infractions.

AUD was defined by ICD codes for main and secondary diagnoses from Swedish medical registries for the following diagnoses: ICD8 and 9: alcohol-related psychiatric disorders (291), alcohol dependence (303), alcohol abuse (305A), alcohol-related polyneuropathy (357F), alcohol-related cardiomyopathy (425F), alcohol-related gastritis (535D), alcoholic fatty liver, alcohol hepatitis, alcoholic cirrhosis, unspecified liver damage caused by alcohol (571A-D), toxic effects of alcohol (980), alcoholism (V79B); ICD10: alcohol6 related psychiatric and behavioral disorders (F10, excluding acute alcohol intoxication: F10.0), rehabilitation of a person with alcohol abuse (Z50.2), guidance and medical advice to a person with alcohol abuse (Z71.4), 
alcohol-related pseudo-Cushing syndrome (E24.4), alcoholrelated degeneration of the nervous system and brain (G31.2), alcohol-related polyneuropathy (G62.1), alcohol-related myopathy (G72.1), alcohol-related cardiomyopathy (I42.6), alcoholrelated gastritis (K29.2), liver diseases caused by alcohol (K70.0K70.9), acute pancreatitis caused by alcohol (K85.2), chronic pancreatitis caused by alcohol (K86.0), treatment of pregnant alcoholic woman (O35.4), toxic effects of alcohol (T51.0-T51.9), and based on Anatomical Therapeutic Chemical (ATC) codes in the Prescribed Drug Register (containing all prescriptions in Sweden picked up by patients from 2005 to 2010): disulfiram (N07BB01), acamprosate (N07BB03), or naltrexone (N07BB04). Additionally, we identified individuals with at least two convictions of drunk driving (law 1951:649) or drunk in charge of maritime vessel (law 1994:1009) in the Crime registers insuring that we did not count arrests in the suspicion register that descried the same event contained in the conviction register.

\section{Appendix B}

Household was ascertained as follows: From 1960 to 1985 (every 5 th year), we used the household identification number from the Population and Housing Census. The household identifica- tion number includes all individuals living in the same dwelling. For the years we did not have data, we approximated the household identification number with the available information from the year closest in time. From 1986 onward (every year), we used the family identification number from the Total Population Register. Family identification numbers are assigned to individuals who are related and who are registered as residing at the same property (each individual can be part of only one family). In addition, adults who are registered at the same property and have children together but are not married are registered as being in the same family.

Geographical status was defined in terms of Small Areas for Market Statistics (SAMS), which are small geographical units defined by Statistics Sweden, the Swedish government statistics bureau. There are approximately 9,200 SAMS throughout Sweden, with an average population of around 1,000. From 1960 to 1970, we had no information on SAMS areas, and therefore we used parishes as a proxy for SAMS for these years. The parishes serve as districts for the Swedish census and elections, and have approximately the same number of inhabitants as SAMS areas. From 1960 to 1985, we only had information for every 5th year, and for that reason we approximated the geographical status with the information from the year closest in time. 